30. V. Markovac and M. Cohen, ibid., 114, 674 (1967).

31. M. Cohen and K. Hashimoto, ibid., 121, 42 (1974).

32. A. J. Davenport and M. Sansone, ibid., 142, 725 (1995).

33. R. O. Adams, J. Vac. Sci. Technol. A, 1, 12 (1983).

34. M. Pourbaix, Lectures on Electrochemical Corrosion, Chap. 4, p. 151, Plenum Press, New York-London (1973).
35. C.-T. Chen and B. D. Cahan, This Journal, 129, 17 (1982).

36. R. G. J. Strens and B. J. Wood, Mineralogical Mag., 43 347 (1979).

37. G. Okamoto, Corros. Sci., 13, 471 (1973).

38. G. D. Christian and J. E. O' Reilly, Instrumental Analysis, 2nd ed., Chap. 7, p. 180, Allyn and Bacon, Boston, MA (1986).

\title{
Oxide Film Formation on a Microcrystalline Al Alloy at Various Temperatures in Neutral Borate Solution
}

\author{
S. C. Thomas* and V. I. Birss* \\ Department of Chemistry, The University of Calgary, Calgary, Alberta T2N 1N4, Canada
}

\begin{abstract}
FVS0812 is a rapidly solidified $\mathrm{Al}$ alloy consisting of an intermetallic (dispersoid) phase, containing $\mathrm{Al}, \mathrm{Fe}, \mathrm{V}$, and $\mathrm{Si}$, surrounded by a predominately Al matrix. The electrochemical behavior and the oxide film structure of FVS0812 were compared to that of its two phases, as well as pure $\mathrm{Al}$, in neutral borate solution at a range of temperatures. While in acidic solution, FVS0812 is unable to form an adherent, thick, porous oxide film, in $60^{\circ} \mathrm{C}$ neutral solution, stable, although substantially thinner, porous oxides are formed on Al, FVS0812, and the matrix. In contrast to its dissolution in acidic medium, the dispersoid phase is retained within the porous film formed on the alloy in neutral solution. However, the dispersoid phase also causes the formation of a somewhat contorted porous oxide structure. Impedance measurements suggest that solution penetration into fine flaws in the barrier oxide at the barrier/porous oxide interface, a phenomenon exacerbated by increased temperature and time at applied potentials, is more prevalent for FVS0812 than for Al and the matrix.
\end{abstract}

\section{Introduction}

The technique of rapid solidification of molten metal permits the production of alloys which are intermediate in nature between crystalline and amorphous materials. The rapidly solidified, microcrystalline Al-based alloy under study in this work was designated FVS 0812 by its developer, Allied Signal, Inc. The composition of alloy FVS0812 consists of 93.2 atom percent (a/o) $\mathrm{Al}, 4.3 \mathrm{a} / \mathrm{o} \mathrm{Fe}, 0.8 \mathrm{a} / \mathrm{o} \mathrm{V}$, and $1.7 \mathrm{a} / \mathrm{o} \mathrm{Si}$. The microstructure of the alloy is described in previous papers. ${ }^{1-5}$ Briefly, alloy FVS0812 consists of 27 volume percent ( $\mathrm{v} / \mathrm{o}$ ) of nearly spherical (ca. $50 \mathrm{~nm}$ ), intermetallic "dispersoids" of nominal composition $\mathrm{Al}_{13}(\mathrm{Fe}$, $\mathrm{V})_{3} \mathrm{Si}$, uniformly distributed throughout a microcrystalline matrix composed of ca. $99.4 \mathrm{a} / \mathrm{o} \mathrm{Al.}{ }^{4}$

The beneficial properties of FVS0812 obtainable through rapid solidification processing ${ }^{6,7}$ have been overshadowed by its reported inability, in practice, to form a sufficiently thick and adherent anodic surface oxide film in standard anodizing solution, e.g., sulfuric acid. In contrast to the porous oxide film produced on conventional Al alloys, which can be up to $100 \mu \mathrm{m}$ thick, the oxide film on FVS0812 alloy reaches a limiting thickness of ca. $2 \mu \mathrm{m}$, as seen by scanning electron microscopy, ${ }^{8}$ and can be removed relatively easily. As reported in a previous paper, ${ }^{5}$ it was determined that this difficulty primarily arises from the presence of the alloy's dispersoid phase and its dissolution in the aggressive, acidic, anodizing medium.

The thickness of the porous oxide film formed on $\mathrm{Al}$ and conventional $\mathrm{Al}$ alloys increases with time as a consequence of the dynamic equilibrium between oxide growth at the metal/oxide interface and field-assisted dissolution, in the acidic medium, of the barrier oxide layer at the oxide/solution interface, located at the pore bases. ${ }^{9-11}$ However, under certain conditions, porous oxide film can be formed in less aggressive solutions, i.e., those normally used to produce barrier oxide films only. ${ }^{12-14}$ In particular, increasing the temperature of the neutral solution has been found to accelerate the transformation rate of barrier to porous oxide film. ${ }^{15-17}$

\footnotetext{
* Electrochemical Society Active Member.
}

Therefore, one of the objectives of this work was to make a comparison of the electrochemistry of pure $\mathrm{Al}$, FVS0812 alloy, and the bulk forms of the matrix and dispersoid phases of the alloy, in neutral boric acid/sodium borate solution at temperatures ranging from that at which only compact barrier oxide forms, i.e., 20 to $60^{\circ} \mathrm{C}$, at which porous films can form on pure $\mathrm{Al} .{ }^{17} \mathrm{~A}$ further objective was to compare the behavior of the dispersoid phase during the oxidation of the alloy in $60^{\circ} \mathrm{C}$ neutral solution with its behavior in room temperature borate buffer solution $^{18}$ and in standard sulfuric acid anodizing solution. ${ }^{5}$ The overall goal of the work was to determine if the anodization of FVS 0812 in $60^{\circ} \mathrm{C}$ neutral medium would be a practical method of growing a well-structured porous oxide film on the FVS0812 alloy surface.

\section{Experimental}

The working electrodes (WE) employed in this study, electrode surface preparation, cell arrangement, instrumentation, and software are detailed in previous papers. ${ }^{5,18}$ Briefly, the WEs included a pure polycrystalline Al rod (geometric area of exposed surface $c a .0 .32 \mathrm{~cm}^{2}$ ), a rod of the extruded form of FVS0812 (ca. $\left.0.27 \mathrm{~cm}^{2}\right)$, material considered to be equivalent in composition to the matrix phase of the alloy and referred to as "matrix" (rod, ca. $0.20 \mathrm{~cm}^{2}$ ), and material considered to be equivalent in composition to the intermetallic phase of the alloy ${ }^{19}$ and referred to as "dispersoid" (chip, ca. $0.25 \mathrm{~cm}^{2}$ ). All current densities $(i)$, capacitances $(C)$, resistances $(R)$, and impedance data $(Z)$ are reported with respect to the geometric surface area of the WE.

The reference electrodes (RE) used were either a calibrated iridium oxide electrode, $c a .0 .43 \mathrm{~V} v s$. the standard hydrogen electrode (SHE), or a sodium saturated calomel electrode. All potentials are referenced to the SHE in this paper.

The neutral solution used was $0.5 \mathrm{~mol} \operatorname{liter}^{-1}$ boric acid/0.025 mol liter ${ }^{-1}$ sodium borate, a buffer solution of $\mathrm{pH} 7.0$, prepared with ACS reagent-grade chemicals, and triply distilled water. Solutions were constantly stirred and deaerated with either argon or nitrogen gas before and during the experiments. The solution temperature was 
controlled to $\pm 0.5^{\circ} \mathrm{C}$ by circulating a fluid of known temperature through the glass jacket which surrounded the $\mathrm{WE}$ and counterelectrode compartments. Comparable experiments were performed at temperatures of 20,40 , and $60^{\circ} \mathrm{C}$. Although the solution in the RE compartment was ca. $25^{\circ} \mathrm{C}$ during experiments conducted at $60^{\circ} \mathrm{C}$, as the basic purpose of the high-temperature work was to compare the behavior of the various substrates, it was not considered essential to know the exact potential of the RE, as long as conditions remained constant throughout an experiment. Therefore, no temperature correction of the potentials are made in this work.

Solutions used in the electrochemical experiments were analyzed to establish the extent of metal dissolution by inductively coupled plasma, atomic emission spectrometer (ICP-AES). Impedance measurements were carried out at $0.1 \mathrm{~V} v s$. SHE in the same solution and at the same temperature as that of film formation. ${ }^{5}$ Thin sections (ca $30 \mathrm{~nm}$ ) of selected oxide-coated samples were prepared by ultramicrotomy and examined by transmission electron microscopy (TEM). ${ }^{5}$ The composition of the ultramicrotomed sections was investigated by energy dispersive $\mathrm{x}$-ray analysis (EDX).

\section{Results and Discussion}

General electrochemical behavior of substrates as a function of temperature.-The $i / t$ response during oxide film growth on $\mathrm{Al}$ and its alloys at constant potential can provide information regarding the type of film that is being formed. A rapidly decaying current to small steadystate values is indicative of compact, barrier film growth, while a small current peak and much higher steady-state currents are a reflection of porous film growth. ${ }^{9,20-22}$ In this work, the effect of temperature on the $i / t$ transients at constant anodizing voltage was examined for the four substrates under study, with the goal being to determine the oxide film properties in each case and to compare the FVS0812 alloy response with that of its individual components and with pure $\mathrm{Al}$.

Typical transients during oxide film formation at $10 \mathrm{~V}$ are shown for only pure $\mathrm{Al}$ and FVS0812 in Fig. 1 at a range of temperatures of the neutral borate solution. For clarity, the transients for the matrix and dispersoid phases are not shown; those for the matrix were always almost identical to those for pure $\mathrm{Al}$, while the current for the dispersoid was very similar in shape but much larger in magnitude, by ca. ten times, than that of the FVS0812 alloy. At all temperatures, the degree of passivity of the substrates, as gauged by the magnitudes of the long time steady-state current densities, $i_{\mathrm{s}}$, show a similar pattern to that reported previously in room temperature acidic solution ${ }^{5}$ and room temperature neutral borate solution, ${ }^{18}$ with the dispersoid material displaying the highest current density, followed by FVS0812, and then the matrix and pure Al.

Figure 1 shows that the transients for $\mathrm{Al}$ at 20 and $40^{\circ} \mathrm{C}$ are typical of barrier film formation, although the currents after $30 \mathrm{~min}$ are ca. four times larger at $40^{\circ} \mathrm{C} \mathrm{vs.} 20^{\circ} \mathrm{C}$. At $40^{\circ} \mathrm{C}$, some dissolution of $\mathrm{Al}$ is inferred, based on the leakage current data; however, the amount of metal dissolved is still too low to be detectable by ICP-AES solution analysis. At $60^{\circ} \mathrm{C}$ a different response is seen for $\mathrm{Al}$, more typical of porous oxide film formation, with a current minimum observed prior to achieving $i_{\mathrm{s}}$. In this work, the current after $30 \mathrm{~min}$ at pure $\mathrm{Al}$ at $60^{\circ} \mathrm{C}$ is almost ten times greater than at $40^{\circ} \mathrm{C}$, implying significant porous type film formation. Solution analysis also provides evidence for porous film formation in $60^{\circ} \mathrm{C}$ neutral solution, as the oxidation of pure $\mathrm{Al}$ at $10 \mathrm{~V}$ for $1 \mathrm{~h}$ results in detectable amounts of $\mathrm{Al}$ in the anodizing solution. These results are consistent with those of Takahashi and Nagayama, who reported the onset of some porous film formation on pure $\mathrm{Al}$ at $40^{\circ} \mathrm{C}$ and the development of significant pore structure in $\mathrm{Al}$ oxide films formed at $60^{\circ} \mathrm{C} .{ }^{17}$ The results for pure Al were also obtained for the matrix material. In fact, all substrates show the typical decaying $i / t$ response of barrier film formation at 20 and $40^{\circ} \mathrm{C}$. However, the higher $i_{\mathrm{s}}$ of

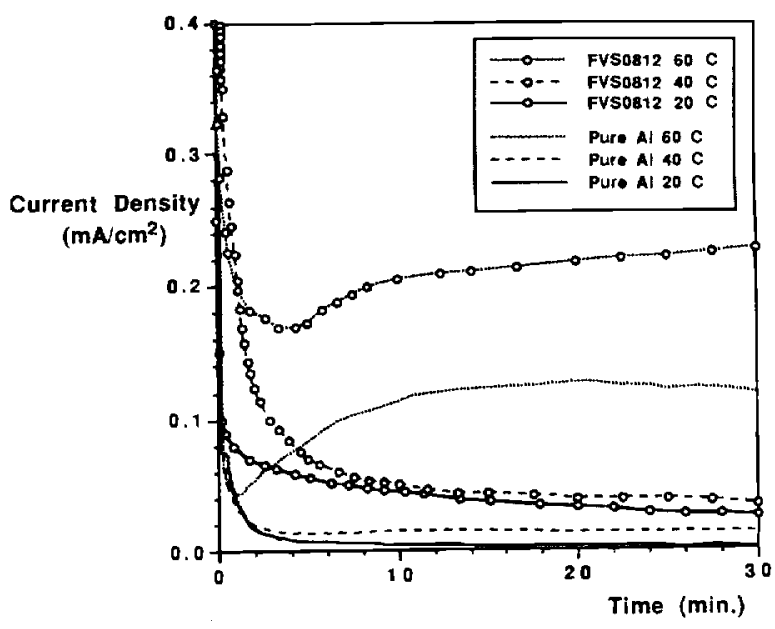

Fig. 1. Effect of solution temperature on current density transients of pure Al and FVS0812 alloy during a hold at $10 \mathrm{~V}$ in neutral boric acid/sodium borate. Data collected during the first $15 \mathrm{~s}$ of potential hold are not shown.

FVS0812 at these two temperatures compared to pure $\mathrm{Al}$ suggests some breakdown of the alloy's oxide film, although again, the amount of metal in solution is not detectable by ICP-AES. In contrast, ICP-AES analysis of the solutions in which oxidation of the bulk dispersoid at $10 \mathrm{~V}$ for $1 \mathrm{~h}$ was carried out shows the presence of $\mathrm{Al}$ and $\mathrm{Fe}$ at all three temperatures and $\mathrm{V}$ and $\mathrm{Si}$ at $60^{\circ} \mathrm{C}$. The absence of significant quantities of $\mathrm{Fe}, \mathrm{V}$, or $\mathrm{Si}$ in the $60^{\circ} \mathrm{C}$ borate solution in which FVS0812 has been oxidized, also at $10 \mathrm{~V}$ for $1 \mathrm{~h}$, provides evidence that dissolution of the dispersoid phase from the alloy and its oxide is not significant under these conditions.

The values of $i_{\mathrm{s}}$ obtained in $60^{\circ} \mathrm{C}$ neutral boric acid/sodium borate are still more than one order of magnitude lower than those obtained for the various substrates in $2.0 \mathrm{~mol} / \mathrm{liter}$ sulfuric acid at $20^{\circ} \mathrm{C}{ }^{5}$ This shows that the rate of porous film formation is lower, consistent with the greater propensity for the dissolution of $\mathrm{Al}$ in acidic media vs. in neutral solutions, even at $60^{\circ} \mathrm{C}$, and suggests that any porous oxide film formed in neutral solution will be thinner than that formed in acidic medium.

Figure 2a compares the first cycle cyclic voltammograms (CVs) for the four metals at $100 \mathrm{mV} / \mathrm{s}$ in $60^{\circ} \mathrm{C}$ neutral borate solution (for clarity, 20 and $40^{\circ} \mathrm{C}$ data are not shown). As with the potentiostatic work, the increase in currents with temperature for all substrates is relatively insignificant from 20 to $40^{\circ} \mathrm{C}$, while a larger increase is seen from 40 to $60^{\circ} \mathrm{C}$. For all substrates, at all temperatures, there is evidence of passive film formation, i.e., a significant drop in current upon potential reversal at the positive limit. In addition, pure $\mathrm{Al}$, the matrix, and FVS0812 show a plateau-like current in the first anodic sweep, suggestive of passive film growth. ${ }^{23}$ The relatively sudden increase in current of the dispersoid material, observed at all temperatures at ca. $1.5 \mathrm{~V}$ (Fig. 2a), probably reflects the onset of both oxygen evolution, which is observed visually, and some metal dissolution, as determined by solution analysis. At all temperatures and sweep rates, the CVs of the dispersoid display the highest charge passed, followed by FVS0812 and then the matrix and pure Al. The larger current densities of FVS0812 at all potentials compared to pure $\mathrm{Al}$ and the matrix is considered to be due primarily to the occurrence of oxygen evolution, observed visually at all temperatures and most probably localized at dispersoid sites, as ICP-AES provides no evidence for significant dissolution of the dispersoid phase from the alloy. It is interesting that when the CV response of FVS0812 is compared with a theoretical $\mathrm{CV}$ based on $73 \%$ of the bulk matrix $\mathrm{CV}$ response and $27 \%$ of the bulk dispersoid $\mathrm{CV}$ response, the ratio of those phases in FVS0812, ${ }^{4}$ a very good fit at $20^{\circ} \mathrm{C}^{18}$ and a reasonable fit at $60^{\circ} \mathrm{C}$ (not shown) are observed, sug- 

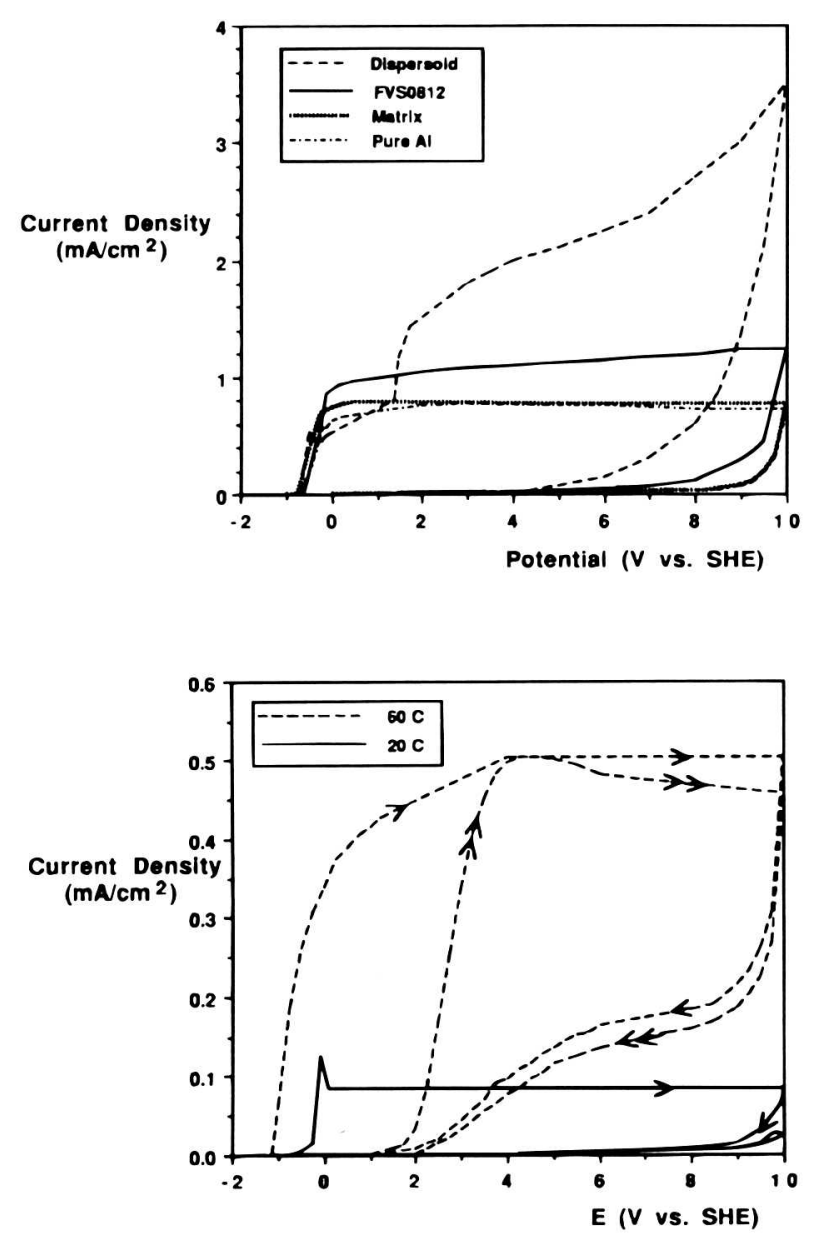

Fig. 2. (a, top) First cycle voltammograms of pure Al, the matrix, FVS0812, and the dispersoid at $100 \mathrm{mV} / \mathrm{s}$ in $60^{\circ} \mathrm{C}$ neutral boric acid/sodium borate. (b, boltom) Cyclic voltammograms of pure Al at $20 \mathrm{mV} / \mathrm{s}$ in 20 and $60^{\circ} \mathrm{C}$ neutral boric acid/sodium borate. Single arrowheads indicate first cycle scans; double arrowheads indicate second cycle scans.

gesting that the electrochemical behavior of FVS0812 alloy proportionally reflects the presence of its two component phases, rather than some unique synergistic effect, at least in the initial stages of oxide growth.

The appropriate combination of sweep rate and temperature can have a significant effect on the voltammograms of pure $\mathrm{Al}$, the matrix, and FVS0812, as indicated in Fig. $2 \mathrm{~b}$ for pure $\mathrm{Al}$. For example, at $20 \mathrm{mV} / \mathrm{s}$ in $60^{\circ} \mathrm{C}$ neutral solution, the current in the second and subsequent cycles achieves a value, at relatively low potentials, approaching that of the plateau current observed in the first cycle. This behavior is reminiscent of that seen in porous-film-forming sulfuric acid ${ }^{5.24 .25}$ and is definitely not characteristic of CVs observed in room temperature barrier-film-forming solution, ${ }^{18}$ where no significant anodic current passes in the second cycle until potentials close to the upper limit of the prior scan are reached, as seen in Fig. $2 \mathrm{~b}$ at $20^{\circ} \mathrm{C}$. These second cycle profiles are not obtained for any substrate at $50 \mathrm{mV} / \mathrm{s}$, conditions under which insufficient time for significant barrier film dissolution and porous film growth would be available, nor at 20 to $40^{\circ} \mathrm{C}$, temperatures too low for significant oxide dissolution to occur.

Transmission electron microscopy/EDX comparison of porous films formed in $60^{\circ} \mathrm{C}$ neutral solution. - Figures 3 to 5 show transmission electron microscopy (TEM) micrographs of cross sections of the oxide films formed on pure $\mathrm{Al}$, the bulk matrix material, and alloy FVS0812, respectively, in $60^{\circ} \mathrm{C}$ neutral boric acid/sodium borate at $10 \mathrm{~V}$ for $30 \mathrm{~min}$. Unfortunately, the brittle nature of the bulk dis-

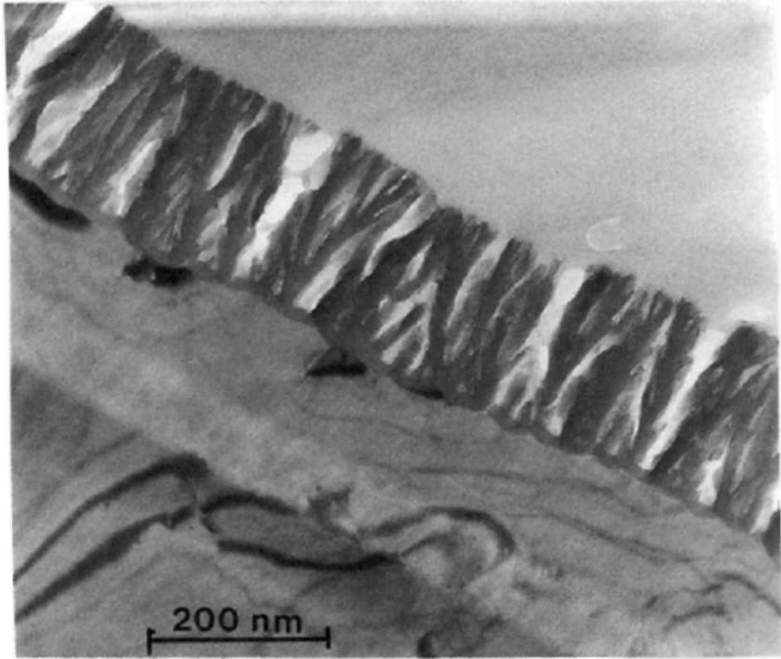

Fig. 3. Oxide film formed on pure $\mathrm{Al}$ in $60^{\circ} \mathrm{C}$ neutral boric acid/sodium borate at $10 \mathrm{~V}$ for $30 \mathrm{~min}$.

persoid material prevented the ultramicrotoming necessary for TEM examination of any oxide formed on the dispersoid surface.

Figures 3 and 4 clearly show that the oxidation of pure $\mathrm{Al}$ and the matrix at elevated temperatures in neutral solution produces oxide films that are very similar in morphology, i.e., a classical porous anodic film with a regular structure of pores passing perpendicularly from the substrate to the outer surface is seen. A thin (estimated to be ca. $17 \mathrm{~nm}$ ), intact, scalloped barrier oxide film of uniform thickness can be seen underlying the porous oxide. The thickness of the barrier oxide provides a ratio of $c a$. $1.4 \mathrm{~nm} / \mathrm{V}$, similar to the results obtained by Takahashi, who reported a thickness/voltage ratio of $1.42 \mathrm{~nm} / \mathrm{V}$ for the barrier oxide underlying the porous film formed on pure $\mathrm{Al}$ in $60^{\circ} \mathrm{C}$ neutral solution. ${ }^{17}$ The thickness of the outer porous layers formed on pure $\mathrm{Al}$ and the matrix after $30 \mathrm{~min}$ of oxidation are also very similar, ca. $200 \mathrm{~nm}$. This value for $10 \mathrm{~V}$ films compares favorably with the $219 \mathrm{~nm}$ reported by Takahashi for anodization of pure Al for 30 min at $50 \mathrm{~V}$ (SCE), also in neutral borate solution, at the same temperature. ${ }^{17}$ The thickness of the porous aluminum oxide formed in acidic solution is known to depend not on the anodic potential but on the length of time of anodizing. ${ }^{11,26}$

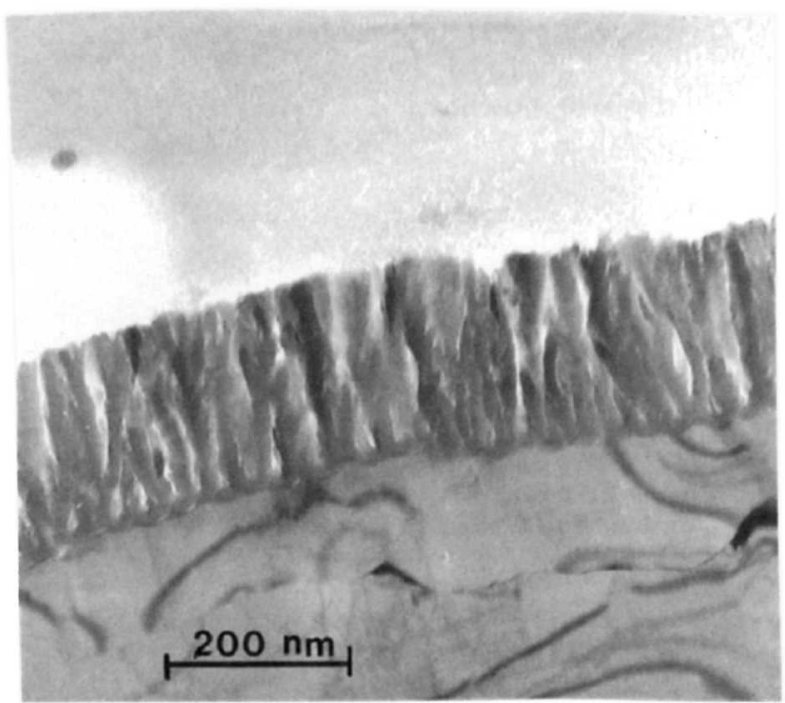

Fig. 4. Oxide film formed on the matrix in $60^{\circ} \mathrm{C}$ neutral boric acid/sodium borate at $10 \mathrm{~V}$ for $30 \mathrm{~min}$. 
Therefore, this relationship appears to hold for porous film formation in neutral solutions as well. While the general appearance of the oxide films formed in $60^{\circ} \mathrm{C}$ neutral solution is very similar to those formed in acidic medium, importantly, however, only a $200 \mathrm{~nm}$ film is formed in the $60^{\circ} \mathrm{C}$ neutral solution in $30 \mathrm{~min}$, whereas only $5 \mathrm{~min}$ was found to be required to form a $1 \mu \mathrm{m}$ film in $20^{\circ} \mathrm{C}, 2.0 \mathrm{~mol} / \mathrm{liter}$ sulfuric acid..$^{5}$

Figure $5 \mathrm{a}$ and $\mathrm{b}$ shows TEM micrographs of cross sections of the oxide film formed on FVS0812 under conditions identical to those of Fig. 3 and 4. A layer of scalloped barrier oxide film, having a very similar thickness as that formed on pure $\mathrm{Al}$ and matrix, is seen on FVS0812 in $60^{\circ} \mathrm{C}$ neutral solution. This barrier oxide layer appears to be almost continuous, in contrast to that formed on FVS0812 in $2.0 \mathrm{~mol} / \mathrm{liter}$ sulfuric acid solution, where the underlying barrier layer was present only intermittently beneath
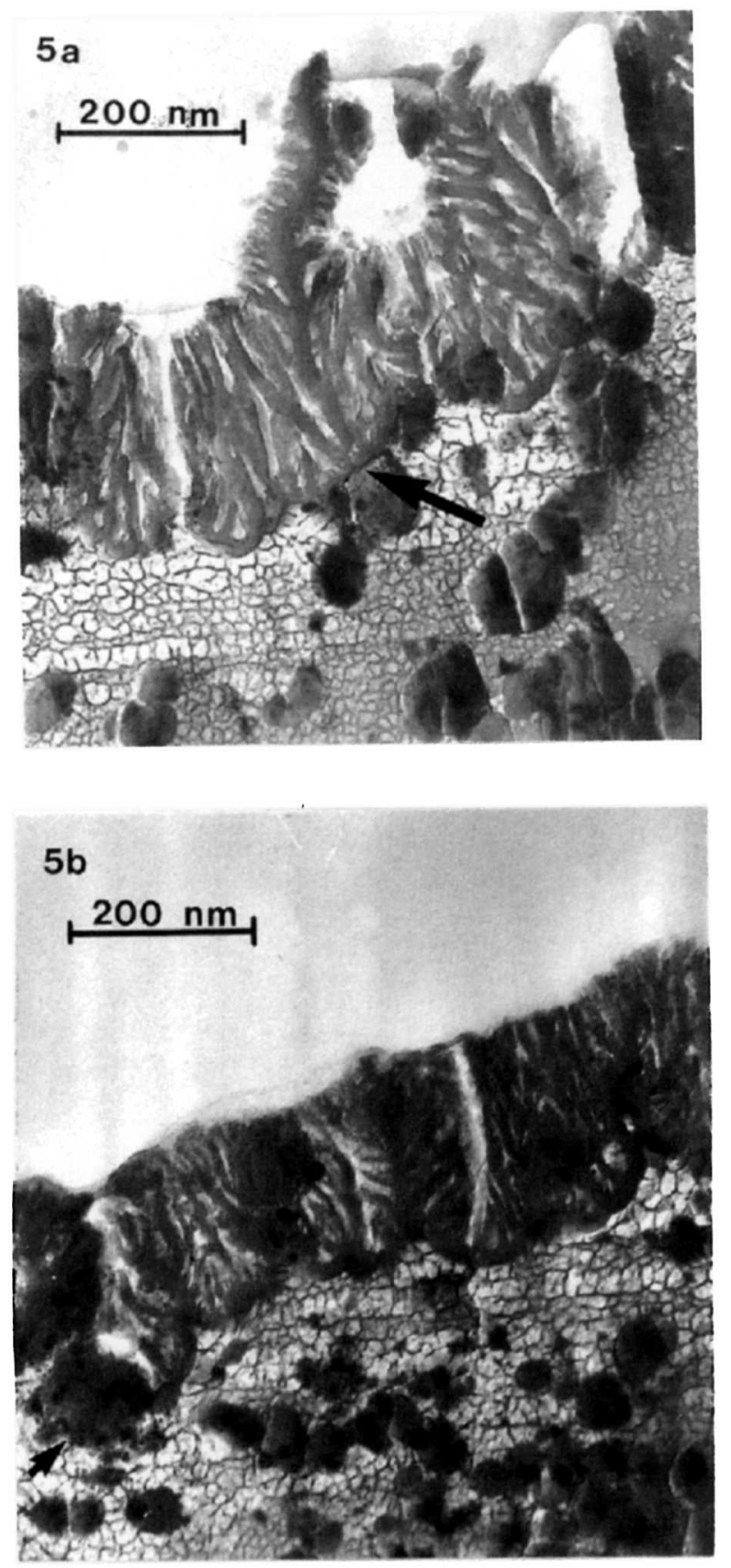

Fig. 5. Oxide film formed on FVSO812 sample in $60^{\circ} \mathrm{C}$ neutral boric acid/sodium borate at $10 \mathrm{~V}$ for $30 \mathrm{~min}$. Arrow indicates (a) barrier layer arrested by dispersoid and (b) dispersoid at metal surface. the porous oxide film. ${ }^{5}$ However, the porous component of the film formed on FVS0812 in neutral solution (Fig. 5a and $b$ ) is contorted compared to the regular structure of the porous film found on pure $\mathrm{Al}$ and the matrix (Fig. 3 and 4). In fact, the morphology of the porous film formed on FVS0812 in $60^{\circ} \mathrm{C}$ neutral solution is quite similar to that formed in $20^{\circ} \mathrm{C} 2.0 \mathrm{~mol} / \mathrm{liter}$ sulfuric acid, although the film is much thicker in acidic media, ca. $700 \mathrm{~nm} .^{5}$ The thickness of the porous oxide film formed in neutral solution appears to range from 200 to $250 \mathrm{~nm}$, comparable to the $200 \mathrm{~nm}$ of porous oxide formed on pure $\mathrm{Al}$ and the matrix under similar oxidation conditions. The nonporous, spheroid-shaped regions, of ca. $50 \mathrm{~nm}$ diam, observed at random locations within both the substrate and the oxide film, have been shown by EDX to be regions of dispersoid material, possibly partially oxide-coated, depending on whether they originated at a pore base or beneath a column of oxide film. The presence of the dispersoid phase within the oxide film provides evidence that the dispersoids have been incorporated, essentially undissolved, into the film, consistent with the results obtained by ICP-AES. The cellular structure which develops beneath the porous film formed on the FVS0812 alloy is of uncertain origin. The dark spots are most likely to have arisen from the partial dissolution, followed by redeposition, of dispersoids during the ultramicrotomy procedure, that is, while the thin metal sections were floating in water. $^{27}$

Figure 5a shows a relatively large open region at the surface of the porous film near the top center of the micrograph. This open region, ca. $100 \mathrm{~nm}$ diam, is roughly twice the size of a dispersoid. It can be hypothesized that this void contained a dispersoid, originally on the surface of the alloy, around which the oxide film had grown. The dispersoid may have fallen out during the electrochemical oxidation procedure or the ultramicrotoming of the sample. Figure 5a (center section) displays a portion of the film where the advancement of the barrier layer into the substrate has been arrested by a dispersoid; the contour of the barrier layer follows that of the dispersoid. Further distortion of the regular structure of the porous film by the presence of the dispersoid phase is shown in Fig. 5b. Curved pores near the dispersoids suggest that oxidation of the matrix phase of the alloy has occurred around the dispersoids. The left side of Fig. $5 \mathrm{~b}$ displays a portion of the film where a dispersoid is at the metal surface. Oxide growth has occurred immediately to the right of the dispersoid and has advanced more deeply into the matrix phase of the substrate alloy; unoxidized matrix is still apparent immediately below and to the left of this dispersoid.

As alluded to previously, EDX analysis of the oxide film formed on alloy FVS0812 at $10 \mathrm{~V}$ in $60^{\circ} \mathrm{C}$ neutral boric acid/sodium borate detected different elements depending on which region of the film was analyzed. Figure 6 shows a Polaroid photograph identifying those regions of the film that were sampled. Regions 1, 2, and 3 of Fig. 6 are dark areas, spheroidal in shape, implying the presence of dispersoid material. The EDX spectra of these regions indicated the presence of $\mathrm{C}, \mathrm{Cu}, \mathrm{O}, \mathrm{Fe}, \mathrm{V}$, and $\mathrm{Si}$, in addition to $\mathrm{Al}$. $\mathrm{C}$ is present as a general contaminant; the $\mathrm{Cu}$ arises from the $\mathrm{Cu}$ grid which supports the samples during analysis. The presence of $\mathrm{Fe}, \mathrm{V}$, and $\mathrm{Si}$ provides further evidence that the dispersoids are incorporated, undissolved, into the porous film formed on the alloy in $60^{\circ} \mathrm{C}$ neutral solution. Whether the dispersoids are incorporated in an unoxidized or partially oxidized state cannot be ascertained, as the origin of the O peak present in the EDX spectrum cannot be unambiguously determined. For example, one explanation for the detection of $\mathrm{O}$ in the EDX spectrum of the dark regions is the presence of an oxide film that would be formed immediately upon exposure of the freshly sectioned substrate to air and the distilled water in the boat of the diamond knife during ultramicrotoming of the specimen. The presence of $O$ in the spectra of the dispersoid regions could also result from the spreading of the x-ray beam, ca. $4 \mathrm{~nm}$ diam, as it passes 


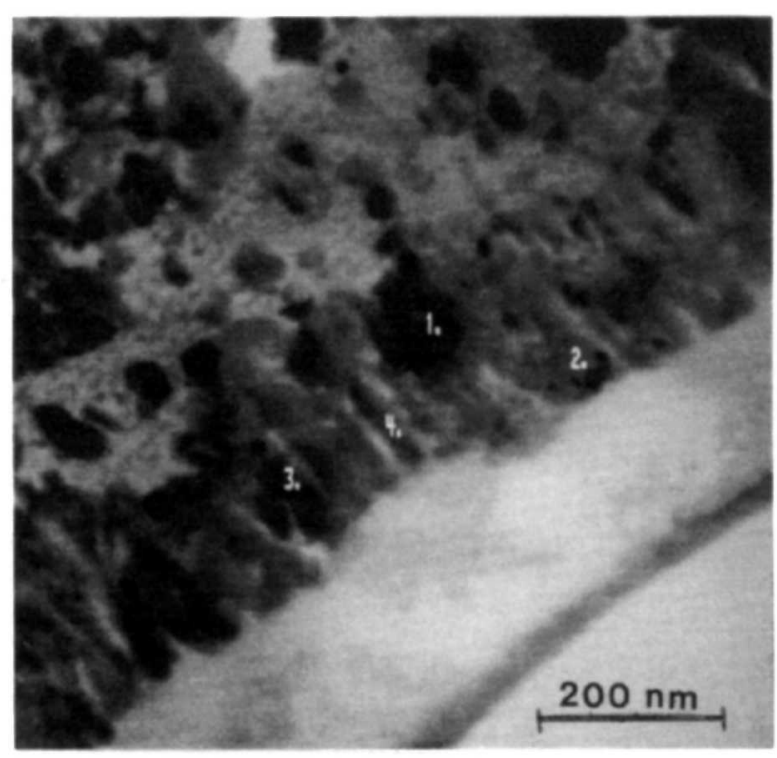

Fig. 6. Polaroid of oxide film formed on FVSO8 12 alloy in $60^{\circ} \mathrm{C}$ neutral boric acid/sodium borate at $10 \mathrm{~V}$ for $30 \mathrm{~min}$. Metal at top, oxide layer in center, and resin at lower portion of photograph. Regions 1, 2, and 3 dispersoid phase, region 4 porous oxide film.

through the region to be analyzed, and beam spreading would result in the analysis of aluminum oxide in the matrix region in addition to the dispersoid material. The EDX spectrum of region 4 in the oxide film (Fig. 6), a region in which no visible dispersoid material is evident, showed no significant presence of $\mathrm{Fe}, \mathrm{V}$, or Si that could arise from dispersoid material; $\mathrm{Al}$ and $\mathrm{O}$ only were identified. The composition of the film in areas bearing no discernible spheroid-shaped dispersoid material appears to be that of normal alumina arising from oxidation of the matrix component of the alloy.

A model for porous film formation on the alloy surface in $60^{\circ} \mathrm{C}$ neutral solution is presumed to involve a mechanism similar to that on pure $\mathrm{Al}$ in acidic solutions, i.e., barrier film growth at the substrate/oxide interface in equilibrium with the field-assisted dissolution of barrier oxide at the pore base, hence maintaining a fixed barrier layer thickness and resulting in an increasing porous layer thickness with time. Significant field-assisted dissolution and some oxide film formation at the dispersoid phase (based on Fig. 2), originally randomly distributed within the matrix material, would occur only when a dispersoid is situated at the base of a pore, where the electric field is large and access to solution is possible. ${ }^{28}$ TEM micrographs show no evidence of pores passing through individual dispersoids, suggesting that oxidation of the FVS0812 alloy is primarily that of the matrix phase around the dispersoids, although oxidation of a dispersoid surface would occur wherever the solution gains access to a dispersoid. Thus, the majority of dispersoids would be incorporated, undissolved, as confirmed by the lack of $\mathrm{Fe}$, $\mathrm{V}$, and Si found in solution, into the growing porous film.

Probing the underlying barrier oxide layer with ac impedance.-The potentiostatic and potentiodynamic results have indicated that the oxide formed on FVS0812 alloy is not as passive as oxides formed on pure $\mathrm{Al}$ and the matrix material, consistent also with the high currents seen at the individual dispersoid phase. Despite this, the porous oxide film thickness on FVS0812 is almost the same as that on $\mathrm{Al}$ and the matrix material, although clear differences in pore structure are seen. Also, TEM micrographs of porous films formed in $60^{\circ} \mathrm{C}$ neutral solution suggest that the barrier oxide underlying the porous film on FVS0812 alloy contains more flaws than the barrier oxide underlying the porous films formed on pure $\mathrm{Al}$ and the matrix. For example, Fig. 5a shows a flaw penetrating the oxide from the surface to the FVS0812 metal substrate with no intervening barrier oxide in between. No such flaw penetration to the metal substrate was seen in micrographs of pure $\mathrm{Al}$ and the bulk matrix material, as shown in Fig. 3 and 4. Therefore, in the present work, ac impedance was employed to attempt to probe the underlying barrier oxide layer formed on the different substrates in 20 to $60^{\circ} \mathrm{C}$ borate solutions in order to distinguish barrier film quality from porous film characteristics as the reason for the higher currents passed at FVS0812 (Fig. 1 and 2). (It is generally agreed that the presence of a thin, unsealed porous oxide film on $\mathrm{Al}$ does not contribute to the overall measured impedance of such a system, ${ }^{29,30}$ and therefore the impedance technique can be expected to yield information about the barrier film.)

Anodic oxide films were grown at selected temperatures at $10 \mathrm{~V}$ for $30 \mathrm{~min}$ and $2 \mathrm{~h}$ by stepping the potential of the WE from open circuit, after which impedance measurements were conducted at $0.1 \mathrm{~V}$ at the same temperature and in the same solution as that of film formation. At all temperatures, the impedances of the oxide films of FVS0812 and on the dispersoid are lower than those of films formed on pure $\mathrm{Al}$ and matrix, with the greatest difference between these materials being seen at $60^{\circ} \mathrm{C}$ (Fig. 7). At all temperatures, the close to -1 slopes of the impedance Bode plots for pure $\mathrm{Al}$, the matrix, and FVS0812 indicate that the barrier oxide films on these substrates are responding capacitatively ${ }^{31}$ over the frequency range of $10^{1}$ to $10^{3}$ $\mathrm{Hz}$, i.e., they have typical dielectric properties. In contrast, the Bode slopes for the dispersoid material over the same frequency ranges are significantly greater than -1 . The different nature of the dispersoid surface is therefore highlighted by this data.

Figure 8 shows the dependence of the overall measured impedance on the ac frequency for oxide films formed on FVS0812 alloy at 20,40 , and $60^{\circ} \mathrm{C}$ in neutral boric acid/sodium borate solution. The impedance of the oxide films formed on FVS0812 decreases with an increase of temperature, with a greater change in impedance occurring between 40 and $60^{\circ} \mathrm{C}$ than between 20 and $40^{\circ} \mathrm{C}$. This same trend with temperature is observed for the bulk dispersoid material. These results correlate with the higher current densities seen at constant potential (Fig. 1) and in the $\mathrm{CV}$ experiments (Fig. $2 \mathrm{~b}$ ) at $60^{\circ} \mathrm{C}$ vs. at 40 and $20^{\circ} \mathrm{C}$. The comparable impedance Bode diagrams for pure $\mathrm{Al}$ and the matrix material at 20,40 , and $60^{\circ} \mathrm{C}$ (not shown) are essentially superimposible, with the impedance decreasing relatively insignificantly with increasing temperature.

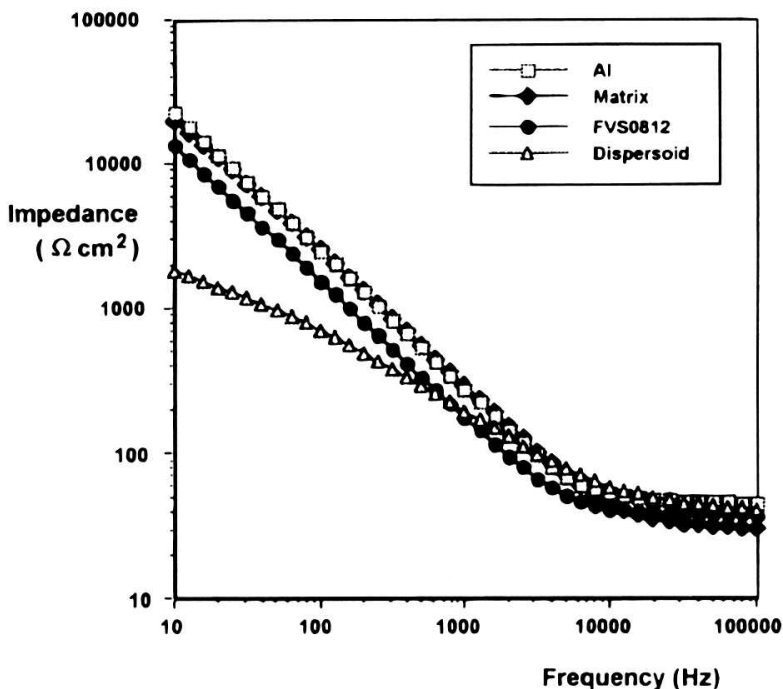

Fig. 7. Comparison of impedance Bode diagrams of oxide films formed on the four substrates at $10 \mathrm{~V}$ for $0.5 \mathrm{~h}$ in $60^{\circ} \mathrm{C}$ neutral boric acid/sodium borate. 


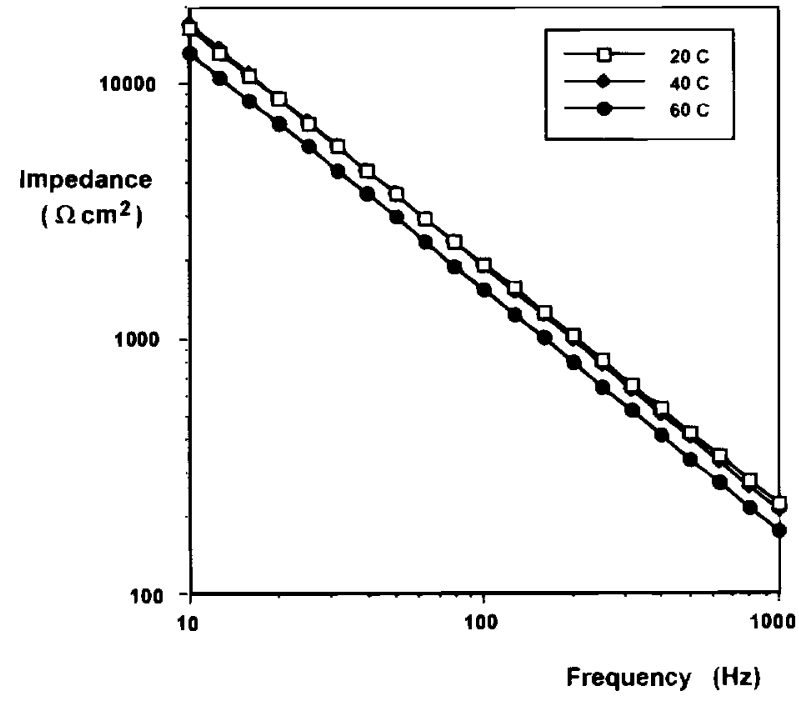

Fig. 8. Effect of temperature on impedance Bode diagrams of oxide films formed on FVSO812 in neutral boric acid/sodium borate at $10 \mathrm{~V}$ for $0.5 \mathrm{~h}$.

The best fit equivalent circuits were identified for the four substrates at the three temperatures by data fitting using EQUIVALENT CIRCUIT software by B. Boukamp, University of Twente. The values of the circuit elements, i.e., the $R \mathrm{~s}$ and constant phase elements (CPEs), are all provided by this software. The CPEs and associated " $n$ " exponents are used to calculate capacitances (C) present in the system. Strictly speaking, a CPE is equivalent to $C$ only when $n=1$. However, a CPE can be converted to $C$ when $n \geq 0.8 .^{5.31}$ As $C$ is inversely proportional to the thickness of a nonconducting dielectric film, ${ }^{32}$ a comparison of the capacitances of the barrier oxides formed beneath the porous films on the substrates can provide some insight as to the relative thicknesses of the barrier films, keeping in mind that the dielectric constant of the oxide may differ from substrate to substrate.

The equivalent circuit which best fits the data obtained for pure $\mathrm{Al}$, and the matrix at 20 and $40^{\circ} \mathrm{C}$ and for FVS0812 at $20^{\circ} \mathrm{C}$ is one with a single $R C$ time constant, consisting of a parallel combination of the oxide $R_{1}$ and $C_{1}$, in series with the solution $R$, in agreement with the literature for a barrier surface oxide on pure $\mathrm{Al}^{30,33}$ Table I shows the values of $R_{1}$ and $C_{1}$ for these cases (the solution resistance is not shown). The data for the dispersoid material at all temperatures, alloy FVS 0812 at 40 and $60^{\circ} \mathrm{C}$, and pure $\mathrm{Al}$ and the matrix at $60^{\circ} \mathrm{C}$ yield two time constants. The best fit equivalent circuit under these conditions con- sists of a second parallel $R$ and $C$ combination $\left(R_{2} C_{2}\right)$ in series with the first (Table I), suggested to reflect the presence of the porous component of the oxide, or the porous surface of the dispersoid material itself. The $n$ values associated with the CPE and used to calculate $C$ are significantly lower for the dispersoid material than for the other substrates at all temperatures (Table I). Values of $n$ which are less than unity can be an indication of impedance signatures arising from inside a porous conducting structure. $^{34}$

Based on the fact that the $R_{1} C_{1}$ pair of elements are seen at all temperatures for all substrates and the similarity of the $C_{1}$ values to those for barrier $\mathrm{Al}$ oxide films found at $20^{\circ} \mathrm{C},{ }^{18}$ the $R_{1} C_{1}$ pair has been assigned to the barrier oxide films here. As found previously at $20^{\circ} \mathrm{C},{ }^{18}$ at all temperatures, $C_{1}$ of the oxide film formed on the alloy is notably larger than the $C_{1}$ of pure $\mathrm{Al}$ and the matrix by $\mathrm{c} a$. 1.5 to 2 times (Table I), while the dispersoid $C_{1}$ is another 2 to 200 times larger than that of the alloy, depending on the temperature. At all temperatures, the $R_{1}$ values, which are thought to reflect the resistance of the film and possibly the reciprocal of the rate of any redox reactions which can occur at the potential used for impedance measurements, appear to be quite similar for pure $\mathrm{Al}$, the matrix material, and alloy FVS0812 but are substantially lower for the dispersoid material. These $R_{1}$ values contain significant error, however, as the frequency was not extended to low enough values to reach the purely resistive response for these three film materials. The higher $C_{1}$ and lower $R_{1}$ values observed for the dispersoid may reflect not only a thinner oxide on the dispersoid surface but also the higher surface area which develops with time due to dissolution.

It is also seen from Table I for pure $\mathrm{Al}$ and the matrix that there is an increase in $C_{1}$ with an increase of temperature, with the largest difference, $c a .10 \%$ for pure $\mathrm{Al}$ and ca. $20 \%$ for the matrix material, occurring between 20 and $40^{\circ} \mathrm{C}$. This suggests that the increasing capacitance with increasing temperature may be due to the thinning of the barrier oxide as it is converted to porous oxide, consistent with the model for porous film growth in acidic media. $C_{1}$ of the oxide film on the dispersoid also increases with increasing temperature, with the largest change being $c a$. two orders of magnitude between 40 and $60^{\circ} \mathrm{C}$. As the oxide cannot be 100 times thinner, this must reflect surface roughening, predicted by the detection of metal dissolution by ICP. Dissolution would be expected to be accelerated at higher temperatures. In contrast to the other substrates, $C_{1}$ for FVS0812 is anomalous, remaining almost constant as the temperature increases from 20 to $40^{\circ} \mathrm{C}$ and then increasing slightly as the temperature increases from 40 to $60^{\circ} \mathrm{C}$.

As the underlying barrier film thickness formed on FVS 0812 at $60^{\circ} \mathrm{C}$ was seen by TEM (Fig. 5) to be very similar to that on pure $\mathrm{Al}$ and the matrix (Fig. 3 and 4 ), their

Table I. Values of the components of equivalent circuits for oxide films formed on the four substrates in neutral borate solution at $10 \mathrm{~V}$ for $0.5 \mathrm{~h}$ at 20,40 , and $60^{\circ} \mathrm{C}$.

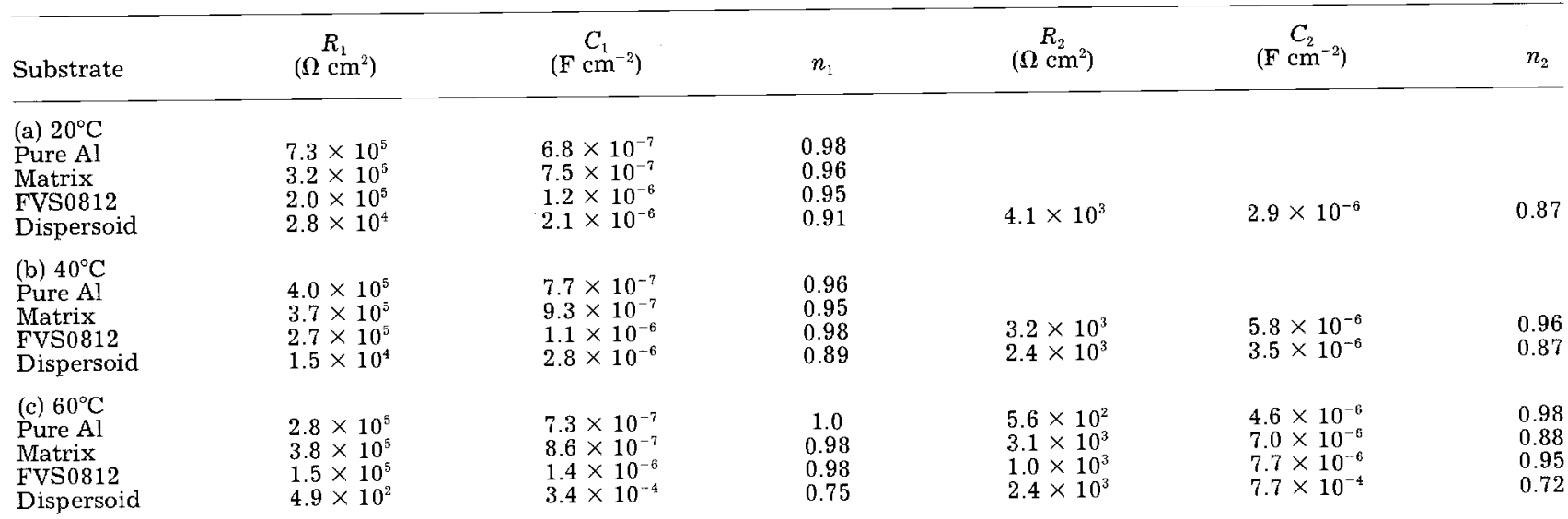


Table II. Effect of time of holding at $10 \mathrm{~V}$ in $60^{\circ} \mathrm{C}$ neutral borate solution on $C_{1}$ values of oxide films formed on pure $A$ and FVS0812.

\begin{tabular}{lcc}
\hline \multirow{2}{*}{$\begin{array}{c}\text { Time } \\
\text { Ch }\end{array}$} & \multicolumn{2}{c}{ Capacitance $\left(\mathrm{F} / \mathrm{cm}^{2}\right)$} \\
\hline \multirow{2}{*}{$\begin{array}{c}\text { Pure Al } \\
0.5\end{array}$} & $1.2 \times 10^{-6}$ & FVS0812 \\
1.0 & $1.1 \times 10^{-6}$ & $1.4 \times 10^{-6}$ \\
2.0 & $0.96 \times 10^{-6}$ & $2.3 \times 10^{-6}$ \\
& & $2.7 \times 10^{-6}$
\end{tabular}

$C_{1}$ values would also be expected to be comparable. However, Table I shows higher $C_{1}$ values for FVS0812 vs. pure $\mathrm{Al}$, for example, ranging from $c a$. 1.8 time greater at $20^{\circ} \mathrm{C}$ to 1.4 times at $40^{\circ} \mathrm{C}$ and back to 1.9 times at $60^{\circ} \mathrm{C}$. This suggests that even at $20^{\circ} \mathrm{C}$, the FVS 0812 barrier oxide may already contain some flaws, i.e., thinner regions of film, which would reduce its overall measured impedance compared to the barrier oxide formed on pure $\mathrm{Al}$ and the matrix material. ${ }^{18}$ These flaws in the oxide formed at $20^{\circ} \mathrm{C}$ are not resolvable by TEM. At $40^{\circ} \mathrm{C}$ for pure $\mathrm{Al}$ and the matrix material, it is quite likely that dissolution of their barrier oxides, accompanied by solvent penetration into flaws, has become more significant, as reflected by the increased $C_{1}$ of the oxides. This would be consistent with the results of Takahashi and Nagayama who reported the onset of porous film formation at $40^{\circ} \mathrm{C} .{ }^{17}$ The $C_{1}$ of the oxide film on FVS0812 remains relatively constant, however, perhaps indicating that pore development occurs at flaws that already existed at $20^{\circ} \mathrm{C}$. At $60^{\circ} \mathrm{C}$, the $C_{1}$ values of the oxides of pure $\mathrm{Al}$ and the matrix increase only slightly from their values at $40^{\circ} \mathrm{C}$, suggesting that pore development occurs at flaws already generated at $40^{\circ} \mathrm{C}$. It is possible that at $60^{\circ} \mathrm{C}$, the dissolution of the barrier layer on FVS0812 during porous oxide growth is accompanied by more severe penetration of the solution into the barrier oxide than at pure $\mathrm{Al}$ and the matrix, resulting in its relatively lower impedance, i.e., higher $C_{1}$ value. Note that the higher capacitances observed for the oxide film at the FVS0812 alloy may also reflect a higher total surface area, as compared to pure $\mathrm{Al}$, due to its dissolution.

The second time constant, $R_{2} C_{2}$, observed at all substrates in $60^{\circ} \mathrm{C}$ neutral solution (Table I), may reflect the presence of the porous oxide, visually observed for pure $\mathrm{Al}$, the matrix, and FVS0812 (Fig. 3, 4, and 5). If this is the case, the presence of $R_{2} C_{2}$ in the equivalent circuit for the oxide formed on FVS 0812 at $40^{\circ} \mathrm{C}$ suggests that the porous

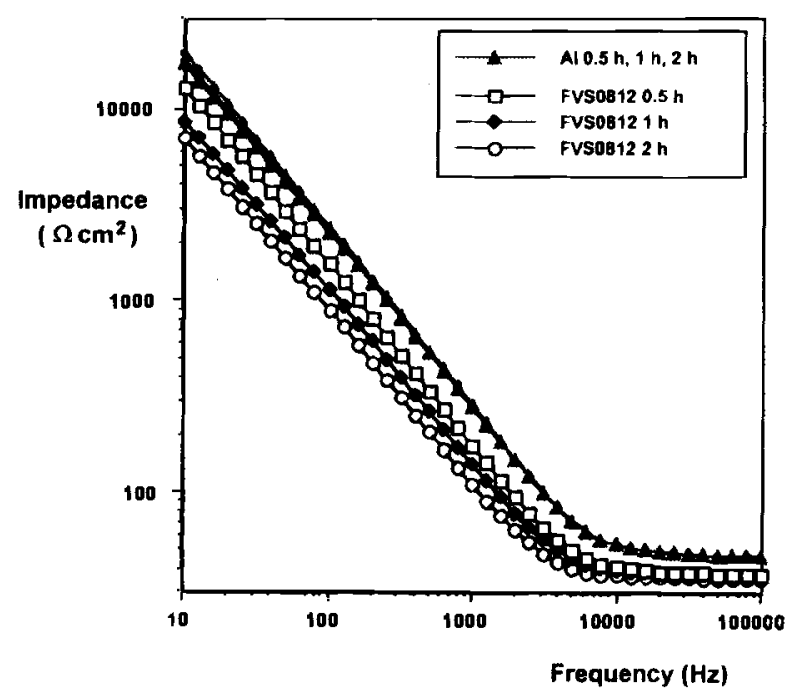

Fig. 9. Effect of time on impedance Bode diagram of oxide films formed on pure Al and FVS0812 at $10 \mathrm{~V}$ in $60^{\circ} \mathrm{C}$ neutral boric acid/sodium borate. component of the oxide is more significantly developed on the alloy than on pure $\mathrm{Al}$ and the matrix at $40^{\circ} \mathrm{C}$. This would not be unexpected, based on the trends in $R_{1} C_{1}$ for FVS0812, discussed previously, indicating a greater number of flaws and incipient porous oxide formation even at room temperature.

Increased time of holding at $10 \mathrm{~V}$ in $60^{\circ} \mathrm{C}$ neutral borate solution causes a further decrease in the impedance (Fig. 9) and increase in $C_{1}$ (Table II) of the oxide film formed on FVS0812, most probably due to the continued dissolution of the underlying barrier film at the barrier/porous oxide film interface. In contrast, there is almost no change in the impedance (Fig. 9) and hence in $C_{1}$ (Table II) with increased time of holding during oxide growth on pure Al. This latter result is consistent with the work of Takahashi et al., who reported that the thickness of the barrier layer underlying a porous oxide formed on pure $\mathrm{Al}$ in $60^{\circ} \mathrm{C}$ neutral borate solution, as determined by TEM, did not change with time of anodizing. ${ }^{17}$ In the present work, the impedance of the film formed on FVS 0812 at $60^{\circ} \mathrm{C}$ does decrease with time of anodization, suggesting that porous oxide growth is accompanied by penetration of the solution into ever-deepening flaws in the underlying barrier film, as well as some possible roughening of the barrier film surface at the pore base due to its dissolution.

Summary of effect of temperature on anodic oxide growth in neutral borate solution.-A comparison of the electrochemical behavior during oxide formation at pure $\mathrm{Al}$, alloy FVS0812, and the bulk forms of the matrix and dispersoid phases of the alloy was undertaken in neutral boric acid/sodium borate solution at temperatures between 20 and $60^{\circ} \mathrm{C}$. Potentiodynamic and potentiostatic studies corroborate the sequence of electrochemical activity obtained previously in acidic solution, ${ }^{5}$ with the dispersoid displaying the highest current density, followed by FVS0812, and then the matrix and pure Al showing the lowest rates of oxidation. For all substrates, leakage currents at constant potential and the anodic potentiodynamic currents increase with increasing temperature, although a significant current increase is seen only above $40^{\circ} \mathrm{C}$. The combined effect of elevated temperature $\left(60^{\circ} \mathrm{C}\right)$ and decreased sweep rate or long times at constant potential promotes the dissolution of the barrier oxide film, especially for FVS0812, and consequent porous film formation in neutral solution. However, for all substrates, a much lower steady-state current density, ca. one order of magnitude less, is seen in neutral solution at $60^{\circ} \mathrm{C}$ compared to that obtained previously in $20^{\circ} \mathrm{C}$ acidic solution, ${ }^{5}$ suggesting a substantially lower rate of porous film formation under these conditions.

TEM micrographs confirm the formation of porous anodic oxide on pure $\mathrm{Al}$, the matrix, and FVS0812 in $60^{\circ} \mathrm{C}$ neutral borate solution. Although the thicknesses of the porous films are similar, ca. $200 \mathrm{~nm}$ after $30 \mathrm{~min}$, their morphology on FVS0812 is more contorted than the regular structure of the porous films formed on pure $\mathrm{Al}$ and the matrix. However, the alloy's porous film appears more structured than that formed in $20^{\circ} \mathrm{C} 2.0 \mathrm{~mol} / \mathrm{liter}$ sulfuric acid. A relatively continuous, interlying barrier oxide layer exists between the substrate and the porous overlayer and most of the dispersoids are retained, undissolved, in the porous oxide film. Importantly, the thickness of the porous film formed on the three substrates is considerably less than that formed in acidic solution, ca. $1 \mu \mathrm{m}$ in $5 \mathrm{~min}$, confirming that the rate of porous oxide growth is substantially less in $60^{\circ} \mathrm{C}$ neutral solutions than in acidic media.

A notable decrease in the impedance of the oxide films formed on FVS0812 and on the dispersoid is seen with increasing temperature, while the impedance of the oxide films varies only slightly with temperature for pure $\mathrm{Al}$ and the matrix. Furthermore, the decrease in impedance of the FVS 0812 oxide at $60^{\circ} \mathrm{C}$ is exacerbated by time spent at constant potential, whereas the impedance of the oxide on pure Al remains essentially independent of time. Although 
examination by TEM of the underlying barrier oxide films formed on pure $\mathrm{Al}$, the matrix, and alloy FVS 0812 at $60^{\circ} \mathrm{C}$ indicates that there is no significant difference in their thicknesses, the capacitance of the oxide on FVS0812 is lower than those of the other two substrates. This corroborates the evidence provided by TEM that flaw penetration of the barrier oxide at the barrier/porous interface is more prevalent at FVS0812 than at pure $\mathrm{Al}$ and matrix. Flaws in the alloy's barrier oxide are most probably present at all temperatures, as indicated by the lower impedance and higher capacitance of the oxide on FVS0812 compared to oxides formed on pure $\mathrm{Al}$ and the matrix. The fact that the impedance changes with temperature implies morphological changes of the film rather than simply the presence of the dispersoid phase as part of the barrier oxide film. This would be expected to lead to a temperature-independent altered dielectric constant and hence an essentially constant capacitance with temperature. At a solution temperature of only $20^{\circ} \mathrm{C}$, these flaws are not resolvable by $\mathrm{TEM},{ }^{5}$ but at $60^{\circ} \mathrm{C}$, the flaws are more severe, penetrating the alloy's barrier layer at the barrier/porous interface, allowing increased solution access and breakdown of the barrier oxide, a phenomenon that increases with time of holding at anodic potentials.

In conclusion, although oxidation in neutral solution at temperatures elevated above those normally used for anodizing does produce a porous oxide on the FVS0812 alloy surface, the film is of inferior quality in terms of its contorted morphology and more flawed barrier layer compared to oxide films formed on pure $\mathrm{Al}$ and the matrix material under the same experimental conditions. The thickness required for abrasion resistance, $c a .25 \mu \mathrm{m}$, does not seem obtainable under the experimental conditions used in this work, considering the length of time required to produce a film of only $0.2 \mu \mathrm{m}$ thickness, $30 \mathrm{~min}$. Furthermore, increased time in the neutral anodizing solution appears to cause further breakdown of the alloy's barrier oxide underlying the porous layer, a phenomenon which may have ramifications for corrosion resistance, although anodization at higher potentials producing a correspondingly thicker barrier layer may compensate for penetration of the barrier oxide by the solution.

\section{Acknowledgments}

Acknowledgment is made to Allied Signal, Incorporated, for providing the FVS0812 alloy, matrix, and dispersoid samples, Don Steele and David Tessier of Alcan International Limited, Kingston Research and Development Center, for assistance and instruction in the techniques of ultramicrotomy and TEM, and Dr. Petr Vanysek of Northern Illinois University for helpful discussion regarding impedance. Financial assistance to V.I.B. and S.C.T. from the Natural Sciences and Engineering Council of Canada, and to S.C.T. from the Alberta Heritage Scholarship Fund, the Canadian Federation of University Women, the Izaak Walton Killam Memorial Scholarship Fund, the University of Calgary Faculty of Graduate Studies, the University of Calgary Department of Chemisty, and A. S. M. International "Calgary Chapter," is also gratefully acknowledged.

Manuscript submitted Jan. 3, 1997; revised manuscript received June 16, 1997.

The University of Calgary assisted in meeting the publication costs of this article.

\section{REFERENCES}

1. D. J. Skinner, R. L. Bye, D. Raybould, and A. M. Brown, Scr. Metall, 20, 867 (1986).
2. D. J. Skinner, R. L. Bye, D. Raybould, A. M. Brown, and M. S. Zedalis, in Processing of Structural Metals by Rapid Solidification, Proceedings of a Seven Session Symposium on Enhanced Properties in Structural Metals via Rapid Solidification, p. 291, ASM International, Metals Park, OH (1987).

3. D. J. Skinner, in Dispersion Strengthened Aluminum Alloys, Y.-W. Kim and W. M. Griffith, Editors, p. 181, The Mineral, Metals \& Materials Society, Warrendale, PA (1988).

4. P. Gilman, Met. Mater, 504 (1990).

5. S. C. Thomas and V. I. Birss, This Journal, 144, 1353 (1997).

6. S. K. Das and L. A. Davis, Mater. Sci. Eng., 98, 1 (1988).

7. S. K. Das, R. L. Bye, and P. S. Gilman, ibid., A134, 1103 (1991).

8. V. I. Birss, Internal report, Allied Signal, Inc., Morristown, NJ (1990).

9. G. C. Wood and J. P. O'Sullivan, Electrochim. Acta, 15, $1865(1970)$

10. G. E. Thompson, Y. Xu, P. Skeldon, K. Shimizu, S. H. Han, and G. C. Wood, Philos. Mag. B, 55, 651 (1987).

11. G. Patermarakis, P. Lenas, Ch. Karavassilis, and G. Papayiannis, Electrochim. Acta, 36, 709 (1991).

12. R. C. Furneaux, G. E. Thompson, and G. C. Wood, Corros. Sci., 18, 853 (1978).

13. P. Skeldon, K. Shimizu, G. E. Thompson, and G. C. Wood, Surf. Interface Anal., 5, 252 (1983).

14. Y. Xu, G. E. Thompson, and G. C. Wood, Trans. Inst. Met. Finish., 63, 98 (1985).

15. R. S. Alwitt and R. G. Hills, This Journal, 112, 974 (1965).

16. G. A. Dorsey, Jr., ibid., 116, 466 (1969).

17. H. Takahashi and M. Nagayama, Electrochim. Acta, 23, $279(1978)$

18. S. C. Thomas and V. I. Birss, This Journal, 144, 558 (1997).

19. D. J. Skinner, Personal communication (1993).

20. J. W. Diggle, T. C. Downie, and C. W. Goulding, Chem. Rev., 69, 365 (1969).

21. G. E. Thompson and G. C. Wood, in Treatise on Materials Science and Technology, Vol. 23, J. C. Scully, Editor, Academic Press, New York (1983).

22. A. Despic and V. Parkhutik, in Modern Aspects of Electrochemistry, Vol. 20, J. O'M. Bockris, R. E. White, and B. E. Conway, Editors, Plenum Press, New York (1989).

23. P. Ll. Cabot, F. A. Centellas, J. A. Garrido, and E. Pérez, J. Appl. Electrochem., 17, 104 (1987).

24. S. C. Thomas and V. I. Birss, in Corrosion, Electrochemistry, and Catalysis of Metastable Metals and Intermetallics, C. R. Clayton and K. Hashimoto, Editors, PV 93-30, p. 38, The Electrochemical Society Proceedings Series, Pennington, NJ (1993).

25. V. I. Birss, S. C. Thomas, and A. J. Zhang, Electrochim. Acta, 40, 1551 (1995).

26. B. Schnyder and R. Kötz, J. Electroanal. Chem., 339, 167 (1992).

27. D. Steele, Personal communication (1992).

28. V. P. Parkhutik and V. I. Shershulsky, J. Phys. D: Appl. Phys., 25, 1258 (1992).

29. B. van der Linden, H. Terryn, and J. Vereecken, $J$. Appl. Electrochem., 20, 798 (1990).

30. J. De Laet, J. Scheers, H. Terryn, and J. Vereecken, Electrochim. Acta, 38, 2103 (1993).

31. P. Vanysek, Introduction to Electrochemical Impedance, The University of Calgary, Canada (1994).

32. A. J. Bard and L. R. Faulkner, Electrochemical Methods Fundamentals and Applications, John Wiley \& Sons, New York (1980).

33. G. R. T. Schueller, S. R. Taylor, and E. E. Hajcsar, This Journal, 139, 2799 (1992).

34. T. Pajkossy and L. Nyikos, ibid., 133, 2061 (1986). 